\title{
Pressure Loss and Heat Transfer Performance for Additively and Conventionally Manufactured Pin Fin Arrays
}

\author{
Kathryn L. Kirsch and Karen A. Thole
}

\begin{abstract}
Pin fin heat exchangers represent a common, viable means of keeping components cool and are widely used for electronics cooling and turbine airfoil cooling. Advancements in manufacturing technology will allow these heat exchangers to be built using new methods, such as laser powder bed fusion, a form of additive manufacturing. New manufacturing approaches, however, render a direct comparison between newly and conventionally manufactured parts meaningless without a good understanding of the difference in the performance.

This research study investigated microchannel pin fin arrays that were manufactured using Laser Powder Bed Fusion and compared them to studies of pin fin arrays from the literature, which are representative of traditionallymanufactured pin fin arrays, where the pin and endwall surfaces exhibited much lower surface roughness. Pin fin arrays with four different spacings were manufactured and tested over a range of Reynolds numbers; pressure loss and heat transfer measurements were taken. Additionally, the test coupons were evaluated nondestructively and the asbuilt geometric features were analyzed.

Measured surface roughness was found to be extremely high in each one of the microchannel pin fin arrays and was found to be a function of the pin spacing in the array, as was the shape of the pin itself; with more pins in the array came higher surface roughness and more distorted pin shapes. Comparisons between the smooth pin fin arrays from literature and the rough pin fin arrays from the current study showed that the high surface roughness more strongly affected the friction factor augmentation than it did the heat transfer augmentation relative to the smooth pin fin arrays.
\end{abstract}

Keywords: Pin fins; heat exchangers; heat transfer; pressure loss; additive manufacturing; laser powder bed fusion

\section{Introduction}

Additive manufacturing ( $A M)$, more generically known as 3-D printing, has emerged as a viable manufacturing technique for heat exchangers in a variety of applications. While the nature of $A M$ relaxes many design restrictions imposed by conventional manufacturing techniques, the specific application of the heat exchanger may heavily dictate its final form.

In thin cross-sectional areas, for example, the cooling method must provide structural support in addition to removing the heat, which is the case in the trailing edge of turbine airfoils. Pin fin arrays are the conventional solution for such scenarios because of the additional convective surface area and because of the increased turbulent mixing in the flow. Pin fin arrays are a widespread and effective cooling technology, most commonly employed to cool electronic and gas turbine components. Even as manufacturing processes evolve and increasingly complex heat exchanger designs become physically realizable, pin fins will remain relevant to the durability of components where high thermal and mechanical stresses are present and where high heat transfer is required.

Certain types of AM are especially applicable to harsh thermal environments. Laser Powder Bed Fusion (L-PBF) methods employ aerospace-grade materials and yield final parts that can endure in gas turbine engines. This paper examines the performance of pin fin arrays produced using DMLS, where pin and endwall surfaces were extremely rough, and compares them to pin fin arrays produced using conventional methods, where both pin and endwall surfaces are much smoother, hereon simply referred to as smooth.

Four pin fin arrays with different spacings were manufactured additively and will be discussed in the context of geometric reproducibility, surface roughness and trends in pressure loss and heat transfer performance when compared to smooth walled pin fin arrays placed in a microchannel.

\section{Literature Review}

Pin fin arrays have been studied extensively and reports on their performance abound in the literature. Many early pin fin studies focused on pin height-to-diameter $(H / D)$ ratios and on pin spacing, in both streamwise $(X)$ and spanwise $(S)$ directions. Chyu et al. [1] varied pin $H / D$ ratios and found that for $H / D=1$, the pin surface contributed to $40 \%$ of the 
total array heat transfer. Metzger et al. [2] performed a row-resolved heat transfer analysis on pin arrays of varying $X /$ $D$ and $S / D$, in addition to varying array orientation [3]; VanFossen and associates [4,5] also studied staggered pin fin arrays and determined an effect of pins' locations in the array on the heat transfer. These studies showed that decreasing $X / D$ and $S / D$ increased the heat transfer, but yielded a corresponding penalty in pressure drop. Armstrong and Winstanley [6] compiled much of this early research and developed power law correlations based on Reynolds numbers; the authors noted that $S / D$ had a stronger influence on friction factor than did $X / D$. More recently, Ostanek [7] developed correlations using Artificial Neural Networks that also took into account array geometry. Lyall et al. [8] and Lawson et al. [9] contributed discussions on Reynolds number effects on both the heat transfer and the pressure drop; an increase in Reynolds number generated higher heat transfer. Siw et al. [10] investigated narrow pin fin channels, where wall effects were influential, and found much increased heat transfer performance when compared to a conventional, wide pin fin array.

Numerous studies on micro pin fin arrays have also been performed, made possible by new manufacturing techniques such as diffusion bonding, stereolithography, chemical etching and LIGA [11]. Some of the studies were motivated by an interest in 1X scale performance for gas turbine airfoil skin cooling [12] and others were focused on small electronics cooling [13-15]. In general, these true scale experiments performed similarly to their scaled-up counterparts in terms of both pressure loss and heat transfer performance, with one exception shown by Heo et al. [15]. Heo et al. manufactured rough pin surfaces and saw an increase in convective heat transfer from the roughened surfaces as compared to the smooth surfaces. The authors tested Reynolds numbers only up to 750 . In a similar vein, Chang et al. [16] artificially roughened the endwall surfaces of a pin fin array and reported higher heat transfer from the roughened channel than a smooth channel at all Reynolds numbers studied, $1000<\operatorname{Re}<30000$. Both studies $[15,16]$ also reported correspondingly high pressure losses from their roughened pin fin arrays.

The additive manufacturing process yields extremely rough surfaces [17], a consequence of the sintering process. One group of studies led by Jodoin [18-20] examined arrays of aluminum pyramidal pin fins that were manufactured additively via Cold Gas Dynamic Spraying. The authors collected bulk heat transfer data and reported good thermal performance coupled with high pressure losses. The authors also performed $\mu$-Particle Image Velocimetry $(\mu \mathrm{PIV})$ measurements and saw turbulence intensities of up to $25 \%$ at $\operatorname{Re}_{\mathrm{Dh}}=500$ [20]; the high surface roughness caused an early transition to turbulence.

Other studies that have taken into consideration the pressure loss and heat transfer performance of additively manufactured finned heat exchangers include those by Ventola et al. [21], Wong et al. [22] and Dede et al. [23], who all used Selective Laser Melting (SLM). The three studies investigated external surfaces only. To note, external surfaces can often be post-processed to reduce the roughness; however, internal surfaces of microchannels prove challenging to post process, especially when the microchannel is filled with objects such as pin fins.

Characterizing surface roughness, among other part features, is important in AM parts and especially so in mini or micro geometries. Ning et al. [24] found that dimensional variances in L-PBF parts are a function of the machine parameters and that smaller geometries are especially prone to such variances due to the natural shrinkage of L-PBF parts, which can reduce the size of small parts (defined as less than $3 \mathrm{~mm}^{3}$ ) by up to $90 \%$. The surface finish of $A M$ parts is a strong function of the process parameters, such as laser scan speed, hatch distance, laser energy density and layer thickness [25-29]. Wegner et al. [28] found that increasing the laser energy density smooths the part surface and mitigates the stair-stepping effect seen on inclined upward facing surfaces. Similarly, Yadroitsev et al. [29] advocated for smaller layer thicknesses to improve surface finish.

Snyder et al. [17], Stimpson et al. [30] and Kirsch and Thole [31] performed detailed pressure loss and heat transfer experiments on L-PBF open microchannels and characterized the surface roughness through the use of a Computed XRay Tomography (CT) scanner. Roughness features were found to protrude deep into open channel space and corresponded to relative sand grain roughness values between $20 \%$ and $38 \%$ the channel hydraulic diameters $[17,30]$. The authors found that the heat transfer augmentation caused by the roughened surfaces plateaued when the friction factor augmentation surpassed four, which corroborated the findings from Norris [32]. Snyder et al. [17] noted that the ability to reproduce a desired channel geometry was a strong function of the build direction, as was the final part's surface roughness. These findings were confirmed in multiple independent studies [26,33,34]. Bacchewar et al. [34] identified laser power as especially influential in the surface roughness of downward facing surfaces; for upward facing surfaces, the laser power had minimal impact on surface roughness. Jamshidinia and Kovacevic [35] found that the proximity of parts during the build process affects the heat accumulation in the part and therefore influences its surface roughness. In Stimpson et al. [36], they expanded upon their initial study in [30] develop a correlation to estimate friction factor given the parts' mean relative roughness, which the authors calculated from SEM images. 
Surfaces with high relative roughness have also been the focus of studies by Huang et al. [37] and Dai et al. [38]. Huang et al. [37] investigated interior pipe walls with uniform surface roughness created by adhering acrylic spheres of a specified diameter to the pipe walls. The relative roughness, or the ratio of acrylic sphere diameter to pipe diameter, reached 42\%; the authors found that friction factor for flow in the subcritical regime exceeded that predicted by laminar theory. Dai et al. [38] focused on liquid flow through mini and micro channels and reported similar results-when relative roughness surpassed 2\%, laminar flow theory under predicted the friction factor. Kandlikar et al. [39] reported a transition to turbulent flow at Reynolds numbers as low as 350 and called for more accurate measures, such as constricted flow area, to represent surface roughness properly.

This summary of relevant work showcases the community's interest in finned heat exchangers and in understanding the additive manufacturing process as it relates to thermal performance. With the wealth of information available on the performance of smooth-walled pin fin arrays and the recent knowledge gained on the surface roughness of AM parts, this paper aims to provide insights into the combined effects of high surface roughness with the complex flow structures so characteristic of pin fin arrays. While external surfaces can be machined or treated to remove roughness features, the internal surfaces of microchannels filled with pin fins are not easily accessible to remedy the surface roughness. The uniqueness of this paper is it is the first to evaluate the use of L-PBF for building microchannels containing pin fins.

\section{Fabrication of Test Coupons}

Four pin fin test coupons were manufactured using L-PBF with its machine's stock Inconel 718 powder [40]. These coupons were constructed in a research laboratory using a commonly available L-PBF machine. The L-PBF machine manufacturer ensured a fully dense final part, so all coupon thermal properties were taken to be that of conventional Inconel 718. The material scaling parameters, beam offset and layer thickness used for the build were those recommended by the manufacturer for Inconel 718 [40]. The layer thickness was set to $40 \mu \mathrm{m}$; the laser focus diameter varied between 100 and $500 \mu \mathrm{m}$ [41].

Table 1. Test matrix

\begin{tabular}{|c|c|c|}
\hline SID & $X / D$ & $\begin{array}{c}\text { Added surface area } \\
\text { relative to open } \\
\text { duct }\end{array}$ \\
\hline 2.0 & 2.6 & $50 \%$ \\
\hline 4.0 & 2.6 & $43 \%$ \\
\hline 1.5 & 2.6 & $58 \%$ \\
\hline 2.0 & 1.3 & $85 \%$ \\
\hline
\end{tabular}

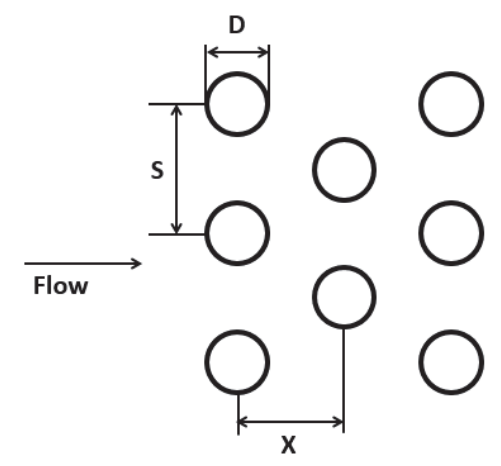

Figure 1. Pin fin spacing nomenclature 


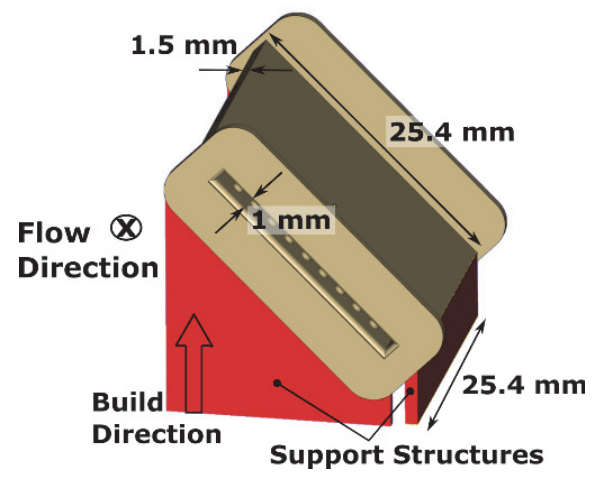

Figure 2. Test coupon build direction, with support structures. Flow direction is into the page, normal to the flanges.

The test coupons were $25.4 \mathrm{~mm}$ in length and in width, and $1.5 \mathrm{~mm}$ in height, which set the endwall thickness in the pin fin array to be $0.25 \mathrm{~mm}$; the open channel hydraulic diameter for each coupon was $1.9 \mathrm{~mm}$. All pin fins were designed to be cylindrical in shape with a diameter of $1 \mathrm{~mm}$ and an $H / D=1$. The test matrix is shown in Table 1 ; a visual description of the pin fin nomenclature used in this paper is shown in Figure 1. An important benefit of pin fin heat exchangers is their addition of surface area over which heat transfer can take place. Given that each of the arrays was confined to a constant volume duct, the number of pins in each test varied and therefore, the convective surface area varied accordingly. The third column in Table 1 shows the percent increase in convective surface area from each configuration compared to an open duct. Three variations in spanwise spacing and two variations in streamwise spacing were constructed and tested at a range of Reynolds numbers between 500 and 25000.

The L-PBF coupons were built layerwise at a $45^{\circ}$ angle to the build plate, in the orientation shown in Figure 2 . For the size of the coupon and the material used, an angle of $45^{\circ}$ ensured that all features with downward facing surfaces would be partially supported [40]. The test section flanges served as anchors for the coupon's support structures during the build.

The coupons were removed from the build plate using a wire electro discharge machine (EDM). Support structures were removed manually from each test coupon and flange surfaces were smoothed to ensure a good seal in the test section as shown in Figure 3.

\section{Geometric Characterization of the Test Coupons}

Due to the locally high temperatures experienced by the part during an L-PBF build, thermal distortion and shrinkage naturally occur. To account for the shrinkage, the L-PBF machine software imposes a geometric scaling factor, as well as a beam offset scalar, with the goal of achieving part dimensions close to the CAD model's. Even still, evaluation of the part's true construction relative to the design intent is crucial for data analysis. To measure such small internal surfaces accurately, Computed X-Ray Tomography (CT Scan) was used.



Figure 3. Picture of L-PBF coupon showing smoothed flange and all support structures removed

The resolution, or voxel size, achievable by the CT scanner used for these experiments was $35 \mu \mathrm{m}$. Data from the CT 
scan were output as 2D slices of the part, showing varying levels of grayscale that corresponded to varying material density. These 2D images were stitched together to form a 3D model of the as-built part using a commercial software [42]. The software was able to achieve surface determinations within $1 / 10^{\text {th }}$ the voxel size, or $3.5 \mu \mathrm{m}$, by using algorithms that compared local grayscale values in each voxel. Therefore, only surface features larger than $3.5 \mu \mathrm{m}$, or $0.35 \%$ of the pin fin diameter, were able to be resolved, which was deemed sufficient for determining the coupons' pertinent dimensions and for calculating the roughness on each of the internal surfaces.

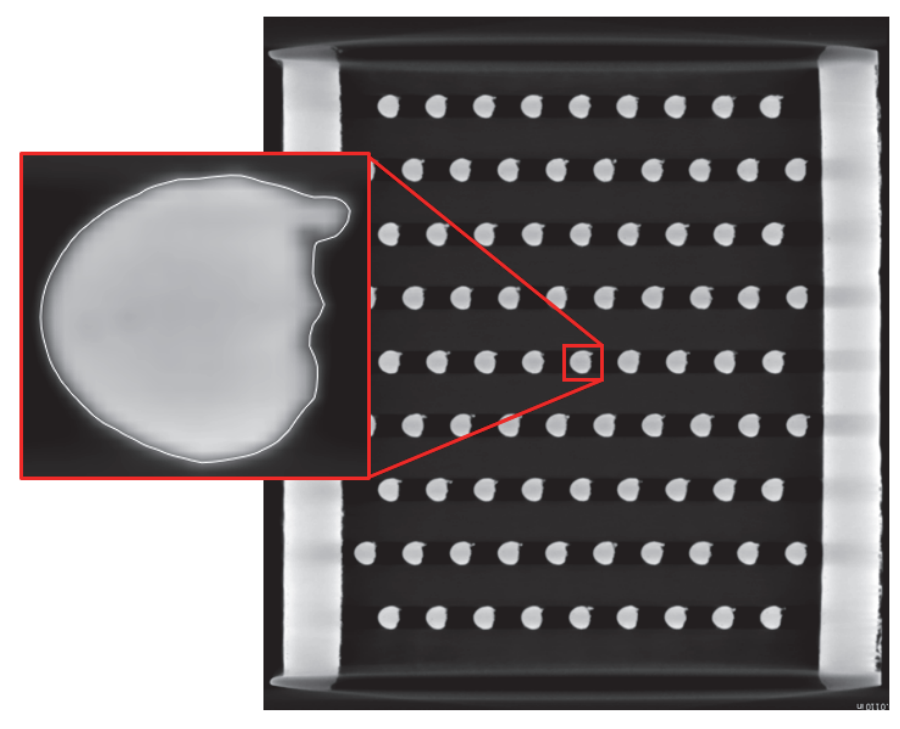

\section{Build Direction | Flow Direction}

Figure 4. CT scan slice of top down view of the $S / D=2.0, X I$ $D=2.6$ coupon, with one pin fin magnified.

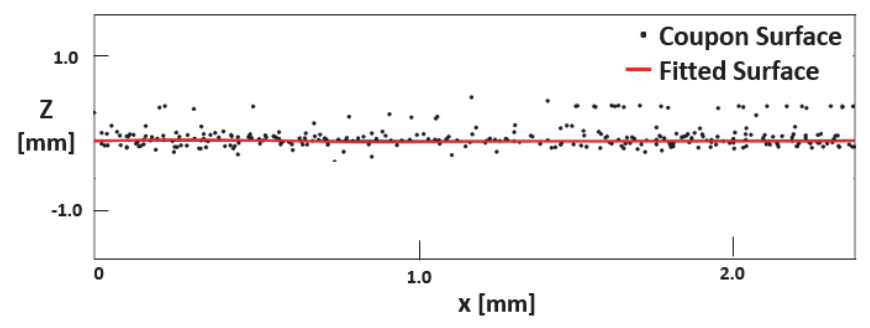

Figure 5. Point cloud data from the CT scan on a small section (2.5 mm long) of a representative bottom surface and its corresponding surface fit, shown in 2D as a curve fit.

The CT scan results showed unmistakably high surface roughness on the test coupon walls; by contrast, the pin surfaces were relatively smooth, though not necessarily circular in cross section. Surface roughness was quantified by fitting a polynomial surface to the top and bottom walls, then measuring the difference between each point on the coupon wall and that fitted surface. That difference was used in the calculation of the arithmetic mean roughness, $R_{a}$, the definition of which is shown in Equation 1. A 2D example of the surface fit (shown as a curve fit) of a small section on one coupon's bottom wall is shown in Figure 5. The roughness features skewed toward positive deviation because of the presence of the pins; the high temperature experienced by the solid pin fins may have caused loose powder particles to stick more readily around the pin base during the build [35]. Typical localized values of maximum peak to valley roughness values ranged between $25 \%$ and $35 \%$ of the channel hydraulic diameter.

Figure 6 shows an image generated by the CT scan from inside the pin fin array; the top wall was expectedly rough, given that it was largely unsupported during the build. In the powder bed fusion process, the laser power is set such 
that the laser penetrates deeper than the current layer, which ensures good adhesion between solid layers. However, on downward facing surfaces, under which no solid material exists to conduct away the heat generated by the laser, large roughness features form.

The bottom walls of the coupons were also extremely rough, the reason for which lies in both the high temperatures experienced by the discrete, solid pin fins, as previously discussed, and in the thickness of the walls themselves. A wall thickness of $0.25 \mathrm{~mm}$ neared the limits of the L-PBF process capabilities to produce a fully dense wall. As the bottom wall of the coupon was built, heat from the laser was not able to be conducted away and the wall remained at an elevated temperature, thus allowing powder particles to become partially sintered to the coupon surface.

Pertinent coupon dimensions were calculated using the $2 \mathrm{D}$ slices output from the $\mathrm{CT}$ scan. Figure 4 shows a mid-height slice from a top down view of the $S / D=2.0, X / D=2.6$ coupon. The build direction relative to the image is shown also, as is the flow direction; due to the build direction chosen, each pin fin had large roughness features that formed on its downward facing surface, consequently rendering the cross sectional shape of each pin not as circular as intended. This formation is visible in Figure 6 as well, on the right side of the pin from the vantage point of the figure. The pins' shapes appeared to be a function of the spacing in the channel.

Figure 7 shows a top down cutaway view of the 3D rendering of two coupons generated by the CT scan; Figure 7a shows the widest spaced array at $S / D=4.0$ and $X / D=2.6$ and Figure $7 \mathrm{~b}$ shows the

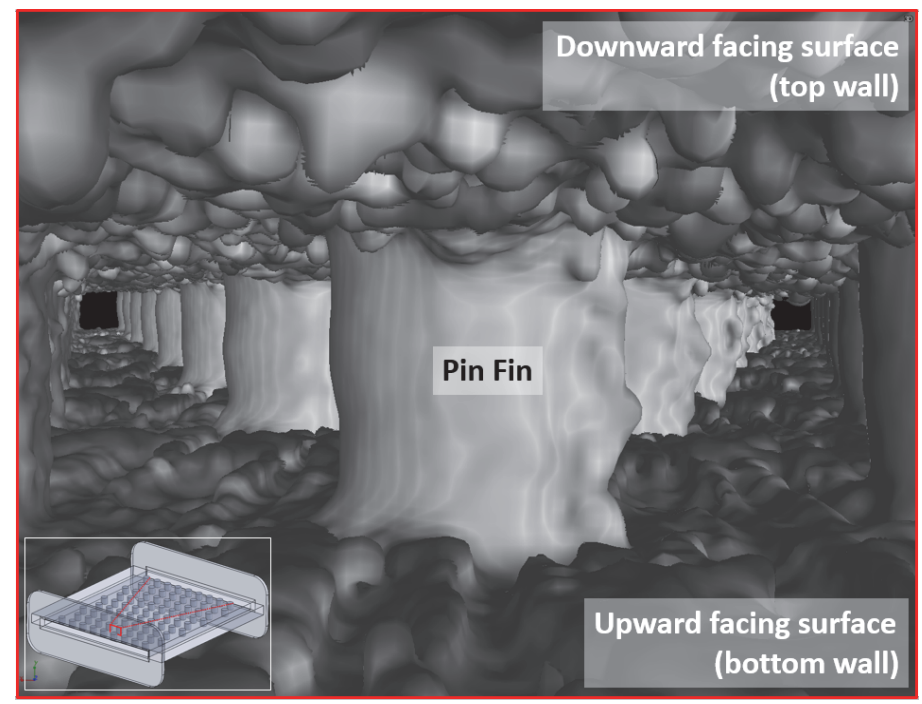

Figure 6. View from inside the pin fin channel; image generated by the CT scan. Flow direction is into the page. The image in the lower left corner shows the location in the test coupon at which the CT scan image was taken.

tightest spaced array at $S / D=1.5$ and $X / D=1.3$. The view area in each figure is equal and the build direction and flow direction match those labeled in Figure 4. In Figure 7, the roughness features that formed on the downward facing surfaces of the pins. The increase in number and size of the roughness features that formed on the downward facing surfaces of the pins are evident in the tighter spaced array (Figure 7b). Additionally, the pin shape between the two arrays was noticeably different. 


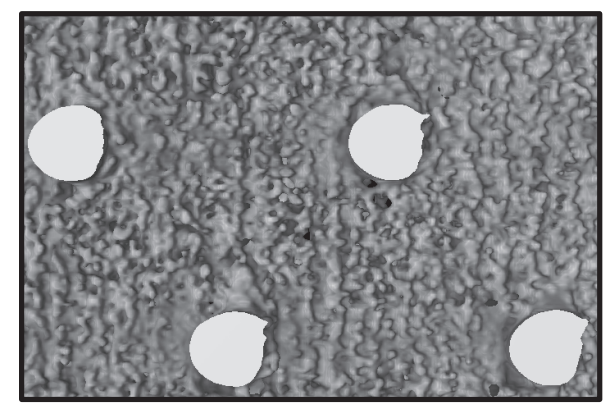

(a)



(b)

\section{Build Direction | Flow Direction}

Figure 7. Top down view of the 3D rendering of as-built test coupons. (a) $S /$ $D=4.0, X / D=2.6$. (b) $S / D=1.5, X / D=1.3$.
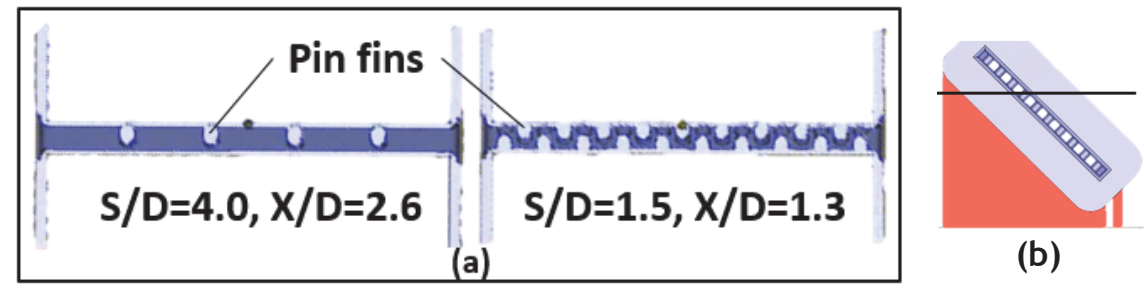

(b)

Figure 8. Laser exposure area for one layer. (a) Top-down view of laser exposure area for two pin spacings. (b) Location of layer slice.

One hypothesis for the supposed correlation between pin density, surface roughness and pin shape lies in the amount of surface area exposed to the laser for each build layer. Figure 8 shows the exposure area, or the amount of material to be melted by the laser, for one layer of the build process for the widest $(S / D=4.0, X / D=2.6)$ and tightest $(S / D=1.5, X /$ $D=1.3$ ) spaced pin fin arrays. A larger amount of surface area requires more time for the laser to melt the metal powder, causing the coupon to experience an elevated temperature for a longer period of time. Such an elevated temperature could cause loose powder particles to adhere to the solid surfaces, thereby incurring a higher surface roughness on the channel endwalls, as well as on the pin surfaces, distorting the pin shapes.

Despite any small extra features on the pin, a pin diameter was calculated as if the cross section were circular by using an in-house image processing code. The cross-sectional area of each pin was calculated using the top-down 2D slices from the CT scan analysis software (Figure 4); from that calculation, an effective pin diameter was backed out. The pin diameter calculations are shown in Table 2, along with the channel hydraulic diameter and the relative roughness of the coupon surfaces normalized by the pin diameter and by the channel hydraulic diameter. The pin diameters were taken as the average of all slices over the entire height of the channel.

Table 2 also shows the fin efficiency $\left(\eta_{f}\right)$ and overall surface efficiency $\left(\eta_{0}\right)$ for each of the pin fin arrays, which were calculated using the methods described in [43]. The overall surface efficiencies were over $97 \%$ for all four arrays. 
Two L-PBF baseline coupons containing multiple rectangular microchannels will be included in the results discussion and will be described briefly here; these microchannel test coupons were studied for friction factor and heat transfer in Stimpson et al. [30]. The coupons were built at a $45^{\circ}$ angle to the build plate, though not in the same orientation as the pin fin arrays. Figure 9 shows the build orientation and the nomenclature to be used for the multichannel coupons. The coupons were manufactured from Inconel 718 and the machine parameters were the same as for the pin fin arrays [40]. Additionally, the coupon dimensions were the same as for the pin fin arrays.

The baseline test coupons were characterized in the same manner described for the microchannels containing pin fins; a CT scanner was used to evaluate the internal surfaces, calculate the surface roughness and determine

Table 2. L-PBF pin fin microchannel coupon dimensions and roughness values

\begin{tabular}{|l|c|c|c|c|c|}
\hline & $\begin{array}{c}S / \\
D=4.0, \\
X / \\
D=2.6\end{array}$ & $\begin{array}{c}S / D=2.0, \\
X / D=2.6\end{array}$ & $\begin{array}{c}S=1.5, \\
X / \\
D=2.6\end{array}$ & $\begin{array}{c}S / D=1.5, \\
X / D=1.3\end{array}$ & $\begin{array}{c}\text { Design } \\
\text { Intent }\end{array}$ \\
\hline Pin $D$ & $\begin{array}{c}0.95 \\
\mathrm{~mm}\end{array}$ & $0.93 \mathrm{~mm}$ & $\begin{array}{c}0.88 \\
\mathrm{~mm}\end{array}$ & $0.90 \mathrm{~mm}$ & $1.0 \mathrm{~mm}$ \\
\hline $\begin{array}{l}\text { Channel } \\
D_{h}\end{array}$ & $2.1 \mathrm{~mm}$ & $2.0 \mathrm{~mm}$ & $1.9 \mathrm{~mm}$ & $1.9 \mathrm{~mm}$ & $1.95 \mathrm{~mm}$ \\
\hline$R_{a} / D$ & 0.074 & 0.088 & 0.09 & 0.10 & -- \\
\hline$R_{a} / D_{h}$ & 0.039 & 0.046 & 0.047 & 0.053 & -- \\
\hline$\eta_{f}$ & $89 \%$ & $89 \%$ & $89 \%$ & $89 \%$ & -- \\
\hline$\eta_{0}$ & $99 \%$ & $99 \%$ & $98 \%$ & $97 \%$ & -- \\
\hline
\end{tabular}

pertinent length scales. Table 3 shows the number of channels in each multichannel coupon from [30], as well as the hydraulic diameter from the design intent and as calculated from the CT scan results.

The channel spanwise spacing is included as well and will be used to distinguish between the two channels in the discussions of the experimental results, consistent with the nomenclature used for the pin fin arrays.



Figure 9. Build direction and nomenclature for LPBF multichannel coupons [30]

The arithmetic mean roughness, normalized by the channel hydraulic diameter, was significantly higher for the L-PBF pin fin arrays than for the L-PBF multichannel array. Where the pin fin arrays contained numerous unsupported surfaces throughout the entire test coupon, in the multichannel test pieces, unsupported surface were confined by continuous fins (walls). The discrete pin fins served as a less effective means to conduct away the heat from the build and consequently yielded higher surface roughness than the multichannel configuration.

Both fin efficiency, $\eta_{f}$, and overall surface efficiency, $\eta_{o}$, were also calculated for the two multichannel L-PBF coupons from Stimpson et al. [30] and are included in Table 3. Both fin and overall surface efficiencies were over $99 \%$ for the multichannel coupons. 
Table 3. L-PBF baseline multichannel coupon dimensions and roughness values [30]

\begin{tabular}{|c|c|c|c|c|}
\hline \multirow{2}{*}{$D_{h}$} & Design & $\begin{array}{c}\text { As- } \\
\text { built }\end{array}$ & Design & $\begin{array}{c}\text { As- } \\
\text { built }\end{array}$ \\
\cline { 2 - 5 } & $\begin{array}{c}0.41 \\
\mathrm{~mm}\end{array}$ & $\begin{array}{c}0.47 \\
\mathrm{~mm}\end{array}$ & $\begin{array}{c}0.83 \\
\mathrm{~mm}\end{array}$ & $\begin{array}{c}0.92 \\
\mathrm{~mm}\end{array}$ \\
\hline $\begin{array}{c}\text { Aspect ratio } \\
(H: W)\end{array}$ & 2.2 & \multicolumn{2}{|c|}{2.2} \\
\hline No. of Channels & 24 & 16 \\
\hline$S / D_{h}$ & 2.1 & 1.55 \\
\hline$R_{a} / D_{h}$ & 0.025 & 0.015 \\
\hline$\eta_{f}$ & $>99 \%$ & $>99 \%$ \\
\hline$\eta_{0}$ & $>99 \%$ & $>99 \%$ \\
\hline
\end{tabular}

\section{Experimental Facility}

Figure 10 shows a cut-away of the test facility used for all pressure loss and heat transfer experiments. This facility has been benchmarked and used in numerous experiments from our laboratory [17,30,31,36,44]. The test section working fluid was air and was pressured to hold a constant inlet pressure of $670 \mathrm{kPa}$ for each Reynolds number tested; the exit pressure was adjusted to attain target Reynolds numbers. All experiments remained in the incompressible flow regime. A commercial gas flow controller was used to control the mass flowrate [45]. The Reynolds number was calculated using the pin diameter and the maximum velocity in the channel, as shown in Equation 2. The maximum velocity was a function of the spanwise spacing of the pins and was calculated using Equation 3 . The inlet and outlet sections were built from Nylon using Selective Laser Sintering to reduce the conductive losses. Static pressure taps were located in these inlet and outlet Nylon pieces to measure the pressure drop across the test coupon. A friction factor was calculated per pin fin row for each experiment using Equation 4, where $N$ is the number of rows in the array. This friction factor definition, sometimes referred to as a flow friction factor [6], is commonly employed among pin fin studies. Its definition is one quarter of the definition of friction factor through channels.

2

In the case of heat transfer tests, copper blocks were heated using a resistive surface heater and served as a constant temperature boundary condition on the coupon endwalls. The surface heaters were directly wired to power supplies that controlled the heat into the system. The assumption of constant temperature boundary condition was validated in a previous study [44]. Thermal paste adhered the surface heater to the copper blocks, as well as the copper blocks to the test coupon. By using a 1D conduction analysis that included both the measured coupon wall thickness and the thermal paste thickness, the temperature of the coupon wall was calculated for the log mean temperature difference. Rigid foam surrounded the copper blocks and provided insulation; additional insulation was inserted in crevices between the foam and nylon to mitigate conduction losses.

Conduction losses were quantified with thermocouples embedded throughout the test section: on the heater itself, in the copper blocks, in the rigid foam and in the Nylon inlet and outlet sections. The highest conduction losses, around $15 \%$ of the total heat into 


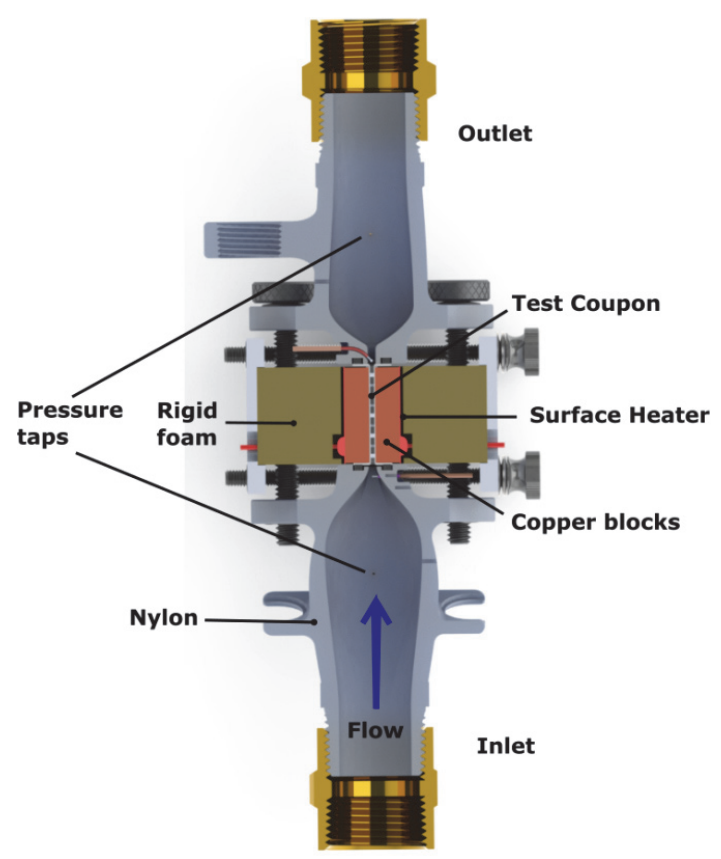

Figure 10. Cross section of experimental test facility

the system, were seen at low Reynolds numbers. For Reynolds numbers above 8000, conduction losses were relatively constant around 5\%. These losses were accounted for in the definition of the heat transfer coefficient as shown in Equation 5. As a check on the heat transfer calculations, an energy balance was performed by measuring the inlet and outlet air temperatures for each test. Comparisons were made between the energy balance of the air passing through the coupon with that of the heat input from the heaters. In all cases, the energy balance matched to within $12 \%$ of the measured heat input, minus the conduction losses.

The heat transfer coefficient was based on the log mean temperature difference as shown in Equation 5 , where $A_{s}$ was the wetted surface area, calculated from Equation 6. In words, Equation 6 represents the surface area of the open channel plus the surface area of the pin fins, minus the pin fin footprints.

\section{5}

6

\section{Experimental Uncertainty}

Experimental uncertainty was calculated using the methods described in Kline \& McClintock [46]. In the friction factor results, the largest source of uncertainty came in the measurement of the pressure drop across the test coupon. At low Reynolds numbers, the pressure loss was low especially in the array with the widest spacing. In those worst case scenarios with the widest spaced array, at Reynolds numbers below 500, uncertainty in the friction factor neared $30 \%$, but quickly dropped to below $10 \%$ for Reynolds numbers greater than 1000 . For the array with the tightest spacing of pins, uncertainty was below $10 \%$ in the friction factor for Reynolds numbers above 500 . However, the repeatability of the datasets, calculated at a $95 \%$ confidence level, was between $1.5 \%$ and $2 \%$ for all Reynolds numbers of interest.

In the case of the heat transfer tests, Nusselt number uncertainty was relatively constant at 5\%. The largest source of uncertainty came in the calculation of the coupon wall temperature using the 1D conduction analysis. Uncertainty in the thickness of the paste that adhered the copper block to the test coupon, along with the uncertainty in wall thickness measured by the CT scan, contributed to the error in calculating the coupon wall temperature. Repeatability in Nusselt number, however, was under 3\% for all Reynolds numbers.

\section{Results and Discussion}

Experiments were conducted on the four L-PBF pin fin coupons to obtain friction factors and Nusselt numbers across a range of Reynolds numbers. These values will be compared to smooth-walled pin fin arrays containing similar streamwise and spanwise spacings. 
Additionally, where applicable, the following graphs will contain data points from an open (no pin fins), smooth, conventionally manufactured test coupon for benchmarking purposes. The smooth channel data points are plotted against common smooth channel correlations. Convention for pin fin array friction factor calculation involves the Fanning friction factor definition, or one quarter the friction factor definition for channel flow. Therefore, a factor of one quarter was applied to the smooth channel correlations: for the flow tests, Laminar Theory $\left(f=16 / \operatorname{Re}_{D h}\right)$ and the Colebrook formula [47] were used in the laminar and turbulent regimes, respectively. For the heat transfer tests, the turbulent Gnielinski correlation was used [48]. The benchmarking coupon was machined from aluminum and contained cylindrical channels that were reamed smooth. Data from the benchmarking coupon matched well to the smooth channel correlations as will be shown in the results.

Despite the deviation from the design intent in pertinent dimensions measured using the CT scan data, as shown in Table 2, the length scales (and consequently, the $U_{\max }$ calculations) for Reynolds number, friction factor and Nusselt number are those from the design intent. The trend in both friction factor and heat transfer results was the same regardless of whether the actual or the design intent length scales were used.

To compare the L-PBF micro pin fin arrays to studies from the literature, applicable previous work will be included in the following graphs. The majority of the comparison studies come from smooth pin fin arrays, but the studies by Stimpson et al. [30] containing L-PBF rectangular microchannels will be included as well; the spanwise spacing of those channels was $S / D_{h}=1.55$ and $S / D_{h}=2.1$. Table 4 shows all previous studies that will be included in the upcoming graphs and notes whether those studies will be discussed in the context of friction factor tests, heat transfer tests, or both.

Table 4. Studies from the literature to be included in results discussion

\begin{tabular}{|c|c|c|c|c|c|c|c|c|}
\hline \multirow[b]{2}{*}{$S / D$} & \multicolumn{2}{|c|}{$\begin{array}{c}\text { Baseline, } \\
\text { Multichannel } \\
\text { Coupon L-PBF } \\
\text { Stimpson et al. } \\
\text { [30] }\end{array}$} & \multicolumn{2}{|c|}{$\begin{array}{c}\text { Ostanek, J.K. } \\
\text { [49] }\end{array}$} & \multicolumn{3}{|c|}{ Lawson et al. [9] } & \multirow{2}{*}{$\begin{array}{c}\begin{array}{c}\text { Brigha } \\
\text { m et } \\
\text { al. [50] }\end{array} \\
4.0\end{array}$} \\
\hline & 1.55 & 2.1 & 2.0 & 2.0 & 2.0 & 4.0 & 4.0 & \\
\hline$X / D$ & $\mathrm{~N} / \mathrm{A}$ & $\mathrm{N} / \mathrm{A}$ & 2.16 & 2.6 & 1.73 & 1.73 & 3.46 & 4.0 \\
\hline$f$ & & $x$ & $x$ & $x$ & $x$ & $x$ & $x$ & \\
\hline $\mathrm{Nu}$ & $x$ & $x$ & $x$ & $x$ & $x$ & $x$ & $x$ & $x$ \\
\hline$R_{a} / D_{h}$ & 0.015 & 0.025 & \multicolumn{2}{|c|}{ Smooth } & \multicolumn{3}{|c|}{ Smooth } & Smooth \\
\hline
\end{tabular}

The following sections will be divided into discussions on (1) pressure loss performance, (2) heat transfer performance and (3) combined friction factor and heat transfer augmentation. Included in these discussions will be the influence of streamwise and spanwise spacing on the array's performance, as well as the effect of varying Reynolds number. Given that the relative roughness in the channels was so high, the discussions will be motivated by the effect of the roughness features on the results when smooth and rough arrays are directly compared. 
1. Pressure Loss Results

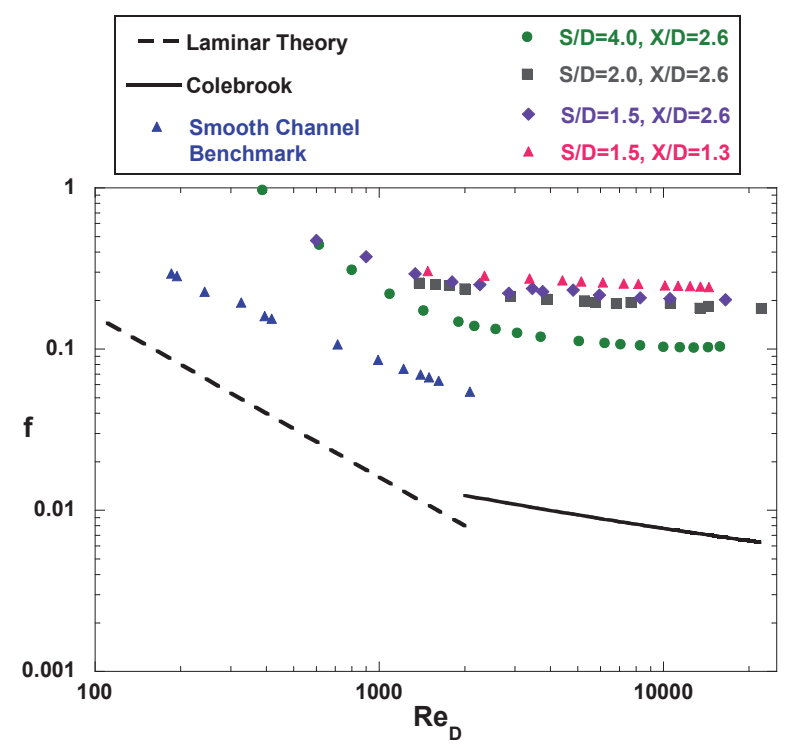

Figure 11. Friction factor results for the four L-PBF pin fin arrays, along with the results from the benchmarking coupon.

Figure 11 shows the friction factor results for the four pin fin arrays in the present study for a range of Reynolds numbers; the friction factor correlations for laminar and turbulent flow are also given, along with the data points from the smooth benchmarking coupon. The friction factor trend for all four microchannel pin fin arrays implies that the fully rough turbulent flow regime was reached between Reynolds numbers of 2000 and 3000, depending on the spacing.

Generally in pin fin arrays, friction factor is driven by the spanwise spacing of the pins because it dictates the blockage to the flow $[2,6,8,9]$. In fact, many correlations for friction factor in pin fin arrays omit any dependence on streamwise spacing and are a function of spanwise spacing, only. For example, Damerow [51] and Jacob [52] include only the spanwise spacing and Reynolds number in their correlations; Damerow [51] claimed that friction factor was not a function of row number. A friction factor correlation given by Metzger [2] is valid only for one spanwise spacing value of $S / D=2.5$, but over a wide range of $X / D$ values, $1.5 \leq X / D \leq 5.0$.

The trend in friction factor seen in Figure 11 does not match with the findings from these previous studies. Friction factor for the L-PBF pin fin arrays correlated with pin density, not solely with spanwise spacing; an increase in the numbers of pins in the coupon led to an increase in the pressure loss through the array. Surface roughness on the top and bottom walls was a function of the number of pins in the channel (Table 2). The coupon with the tightest streamwise and spanwise spacings $(S / D=1.5, X / D=1.3)$ showed roughness values $35 \%$ higher than the coupon with the widest spacings $(S / D=4.0, X / D=2.6)$ (Table 2), a discrepancy hypothesized to be related to the difference in laser exposure area between the two coupons. Therefore, even coupons containing the same spanwise spacing $(S / D=1.5)$, but different streamwise spacings $(X / D=2.6$ and $X / D=1.3)$ exhibited different friction factor values, which is not normally reported in the literature.

To isolate the effects of surface roughness, the friction factor from the L-PBF arrays can also be compared to studies of smooth-walled pin fin arrays of similar spacings $[9,49]$. To note, the studies from $[9,49]$ were scaled up by an order of magnitude. However, the Reynolds numbers tested for the scaled up pin fin arrays match the Reynolds numbers tested in the current study.

Figure 12 shows the friction factor augmentation of the L-PBF coupon with spacing $S / D=2.0, X / D=2.6$, along with three previous smooth walled pin fin studies with $S / D=2.0$, over a smooth channel; the three streamwise spacings of the smooth walled studies were 1.73D, 2.16D and 2.6D [9,49]. Additionally, friction factor augmentation from the L-PBF straight rectangular multichannel study with no pin fins but channel spacing $S / D_{h}=2.1$ is included [30]. 


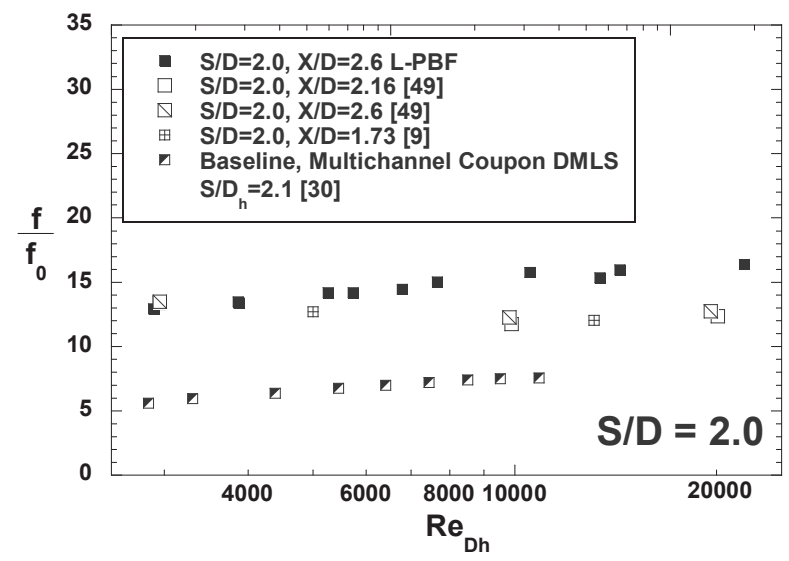

Figure 12. Friction factor augmentation from both DLMS and smooth walled pin fin arrays, along with LPBF straight microchannels with $S / D_{\mathrm{h}}=2.0$ [30].

The friction factor augmentation values were calculated using the conventional definitions for the test coupon at hand. For the pin fin arrays, $f_{0}$ was calculated using the same correlations applied in Figure 11, or one quarter the smooth channel correlations for channel flow. For the multichannel array, the smooth channel friction factor was calculated using traditional channel flow correlations, Laminar Theory (64/Re) and the Colebrook formula [47]. The Reynolds number definition used for the augmentation plots was the duct Reynolds number, as opposed to the pin Reynolds number. The augmentation values, therefore, are comparable between the two types of microchannels.

Figure 12 shows that the augmentation values from the pin fin arrays, both L-PBF and smooth, were substantial. The difference in friction factor augmentation between the L-PBF and the smooth walled pin fin array grew with increasing Reynolds number; at low Reynolds numbers, the friction factor augmentation from the pin fin arrays was similar, regardless of surface finish. However, at higher Reynolds numbers, the L-PBF pin fin array showed near $35 \%$ higher augmentation over the smooth walled arrays. Given that the average size of the roughness features in the L-PBF coupon was $9 \%$ of the pin diameter (Table 2), the flowfield in the array was affected not only by the presence of the pins, but also by the large roughness features on the endwalls and the non-circular nature of the pins themselves.

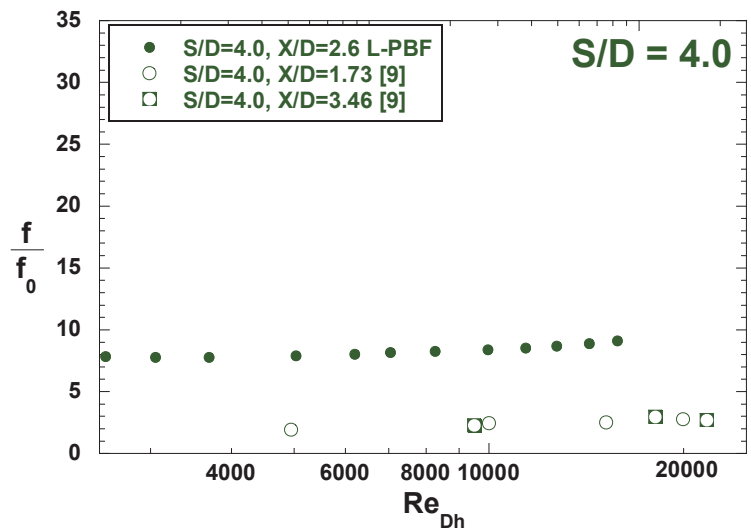

Figure 13. Friction factor augmentation from the LPBF pin fin array over smooth walled pin fin arrays with $S / D=4.0$.

In directly comparing the two L-PBF studies, the pin fin array showed two to three times higher friction factor augmentation than the straight channels [30]. The disparity in friction factor augmentation can be explained primarily by the differences in the flowfields. While the pin fins produced high levels of turbulence and wake shedding, the multichannel coupon with no pin fins was similar to that of channel flow with very rough walls.

In Figure 13, where spacings of $S / D=4.0$ are compared, the friction factor augmentation showed a relatively consistent higher friction factor augmentation over their smooth-walled counterparts. However, much like the L-PBF pin fin array spaced at $S / D=2.0$, the roughness in the array with $S / D=4.0$ more strongly affected the pressure loss through the array 
at Reynolds numbers above 10000. At a Reynolds number of 15000 , the $S / D=4.0$ L-PBF pin fin array showed friction factor augmentation around four times that of the $S / D=4.0$ smooth walled arrays.

\section{Heat Transfer Results}

Figure 14 shows the Nusselt numbers for each of the four L-PBF coupons, along with the data points from the benchmarking coupon and the Gnielinski correlation. All four of the L-PBF coupons showed a considerable increase in the heat transfer as compared to the smooth channel correlation as well as the multichannel L-PBF baseline with no pin fins [30]. While the difference among the four L-PBF coupons was relatively small, two trends emerged that compared well to trends observed in the literature. Tighter spanwise spacing generally yields higher heat transfer than wider spanwise spacing [2,9], which was the case for the L-PBF coupons with $S / D=4.0$ and $S / D=2.0$. However, the difference in Nusselt number is small when the difference in spanwise spacing is marginal [49], as was the case in the $\mathrm{L}-\mathrm{PBF}$ coupons spaced at $S / D=2.0$ and $S / D=1.5$. The second trend was that for a given spanwise spacing, a tighter streamwise spacing generally yields higher heat transfer $[9,49]$; that trend was evident in the L-PBF coupons with $S /$ $D=1.5, X / D=2.6$ and $S / D=1.5, X / D=1.3$.

The high surface roughness in the coupons affected the heat transfer of the L-PBF pins relative to their smooth walled counterparts, especially at higher Reynolds numbers and tighter spacings. Ostanek [49] found that turbulence on the endwalls of pin fin arrays

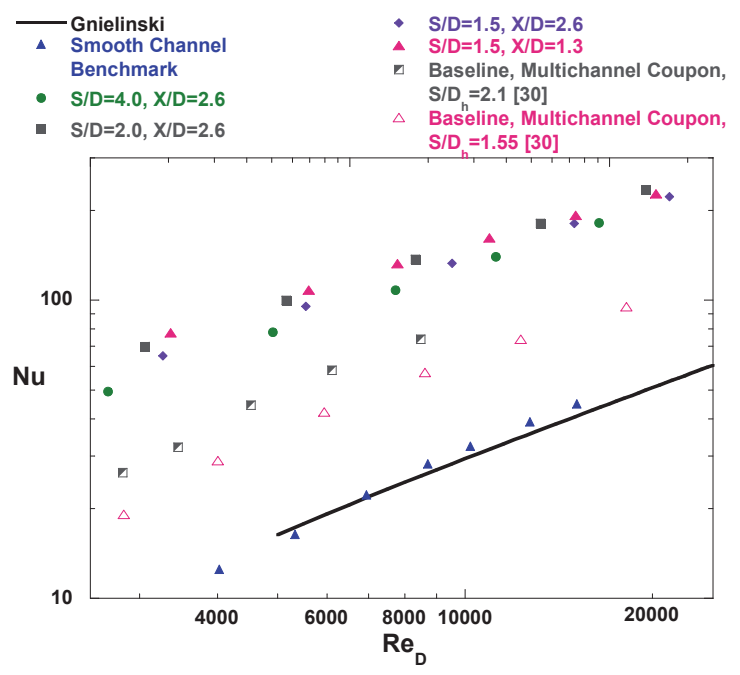

Figure 14. Nusselt number vs. Reynolds number for the four AM pin fin arrays, along with the results from the benchmarking coupon.

provided the most significant contribution to the heat transfer from the arrays; increasing the roughness on the endwalls increased the turbulence and therefore increased the overall heat transfer. Figure 15 shows the Nusselt number augmentation over a smooth duct of the L-PBF coupon with $S / D=2.0$, along with smooth walled pin fin arrays from the literature also spaced at $S / D=2.0[9,49]$. While streamwise spacing exerts a minimal effect on the pressure drop through the array, it strongly affects the heat transfer because it influences the wake formation and wake interactions among the pins [9]. Both streamwise and spanwise spacing prove influential in the final heat transfer results of any pin fin array. The chosen combination of streamwise and spanwise spacings in the L-PBF coupons with S/ $D=2.0$ led to strong wake interactions [53], which were presumably enhanced by the high surface roughness in the channel. As Reynolds number increased, that effect was magnified: the difference between the smooth walled and LPBF pin fin arrays grew with increasing Reynolds number. Additionally, given that the cross sectional shape of the L-PBF pin fins was not perfectly circular, the wakes behind the L-PBF and smooth walled pin fins were assumed to be different. 


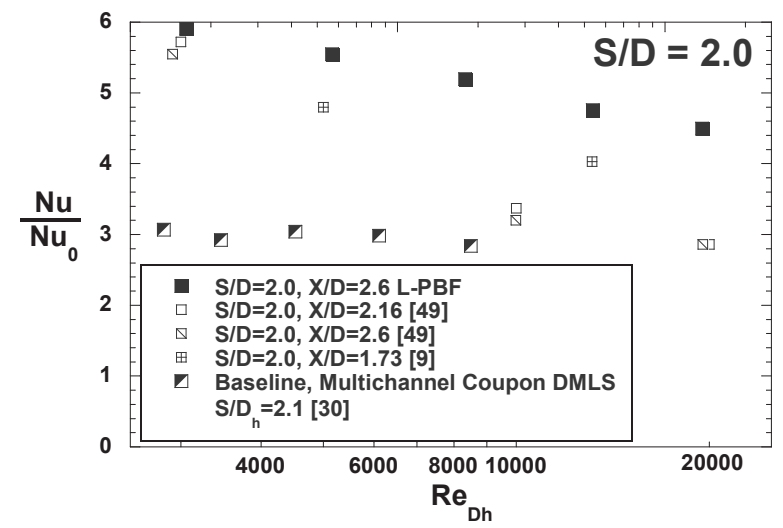

Figure 15. Nusselt number augmentation of L-PBF and smooth walled arrays with $S / D=2.0$.

Figure 16 shows the Nusselt numbers of both L-PBF and smooth walled pin fin arrays with $S / D=4.0[9,50]$. The L-PBF coupon showed similar performance to the smooth walled coupons. While the high surface roughness in the AM coupon undoubtedly added to the already turbulent flowfield in the array, the wide spanwise spacing in the array meant that the pin wake interactions were nevertheless limited [53]. Therefore, in directly comparing the L-PBF pin fin arrays with the smooth walled arrays, the effect of surface roughness on the flowfield as it related to heat transfer was minimal for pins with relatively wide spacing $S / D=4.0$.

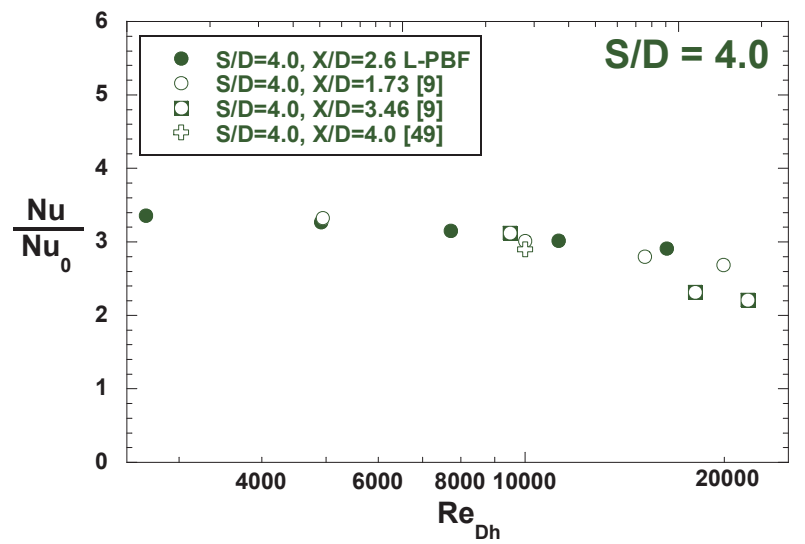

Figure 16. Nusselt number augmentation of L-PBF and smooth walled arrays with $S / D=4.0$.

In Figure 17 and Figure 18, the friction factor augmentation and heat transfer augmentation for pin fins made using LPBF compared with those made using conventional methods are directly compared; a low Reynolds number case is shown in Figure 17 and a high Reynolds number case is shown in Figure 18. Both figures highlight the observation that the increase in friction factor augmentation far outweighed the increase in heat transfer augmentation for the $S / D=4.0$ array. As previously discussed, the high surface roughness on the endwalls strongly affected the friction factor through the L-PBF array relative to its smooth counterpart; on the other hand, the wake interactions from the pins were limited by the wide spanwise spacing, which resulted in negligible differences in the heat transfer between smooth and rough arrays. These two effects accounted for the large discrepancy between friction factor augmentation and heat transfer augmentation seen in both Figure 17 and Figure 18.

\section{Overall Augmentation Results}

To gain a better understanding of how the data from the current study relates to the large amount of research available in the literature, friction factor and heat transfer performance can be analyzed concurrently. Figure 19 shows friction factor augmentation vs. Nusselt number augmentation for the four L-PBF coupons from the current study, along with six other studies from the literatures. Two of the previous studies [30,31] were also manufactured using L-PBF; the other four are representative of commonly-employed internal cooling schemes $[3,9,49,54]$. 


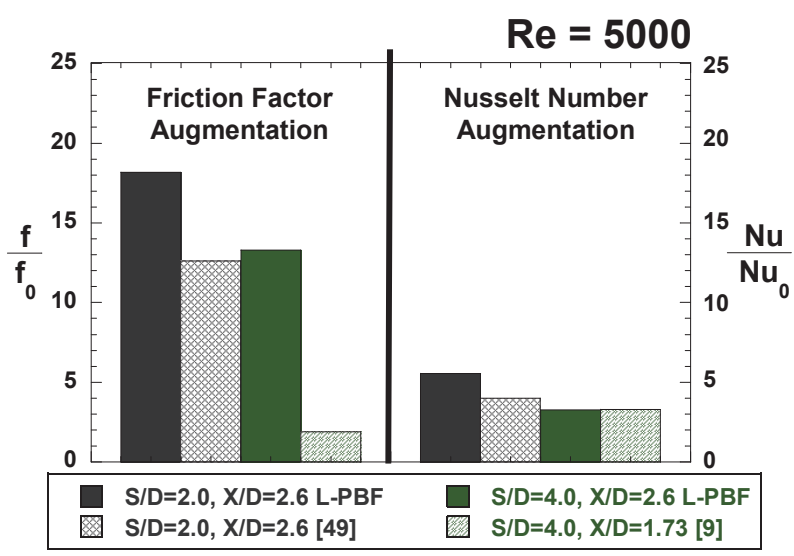

Figure 17. Direct comparison of friction factor augmentation and Nusselt number augmentation of smooth walled and L-PBF pin fin arrays with $S / D=2.0$ and $S / D=4.0$ at $\operatorname{Re}=5000$.

With the exception of the ribbed channel study [54], the friction factor augmentation of the four L-PBF pin fin arrays far surpassed most of the previous studies, with only a slight benefit in Nusselt number augmentation. In general, the L-PBF coupon with the widest spacing of pins $(S / D=4.0, X / D=2.6)$ showed similar heat transfer performance as the other three spacings for less of a pressure loss.

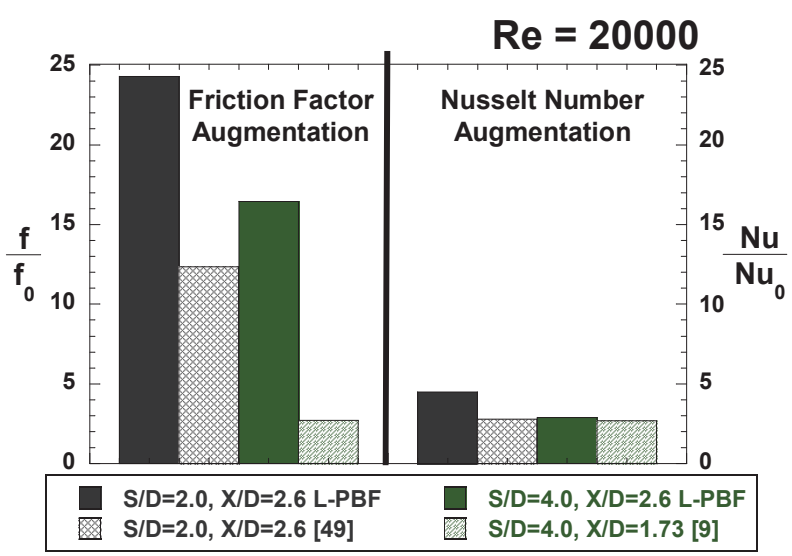

Figure 18. Direct comparison of friction factor augmentation and Nusselt number augmentation of smooth walled and L-PBF pin fin arrays with $S / D=2.0$ and $S / D=4.0$ at $\operatorname{Re}=20000$.

Due to the roughness inherent in the L-PBF process, and the supposed positive correlation between pin density and surface roughness, this result is important to understand for heat exchanger designers. The coupon with the widest spacing $(S / D=4.0, X / D=2.6)$ had one sixth the number of pins as the coupon with the tightest spacing $(S / D=1.5, X /$ $D=1.3$ ). The fact that the same heat transfer augmentation can be achieved with a reduction in the number of pins can lead to material and cost savings in engine components.

In comparing the multiple L-PBF microchannel studies, the pin fins exhibited a significantly higher friction factor augmentation than either the straight or wavy L-PBF multichannel coupons. The arithmetic mean roughness to hydraulic diameter ratio in the L-PBF channels was one quarter that seen in the pin fin arrays [30,31], which most likely contributed to the difference in friction factor augmentation seen in Figure 19. However, the different flowfields between the pin fin arrays and the channel flows were inherently different and were the predominant drivers of the difference in friction factor augmentation. Especially at low Reynolds numbers, the wavy microchannels show similar heat transfer performance to the pins, with considerably less of a penalty in pressure loss.

Given that flowrates in many applications are governed by fixed supply and exit pressures, a small study was done on the L-PBF pin fin arrays to determine the required mass flow at a given pressure ratio, as compared to a smooth duct. 
The mass flow through the smooth duct was calculated using a friction factor correlation and the target pressure ratio from the L-PBF coupon. For the tightest spacing of pins $(S / D=1.5, X / D=1.3)$, the flowrate through the L-PBF array was reduced by $90 \%$ to achieve the same pressure ratio across a smooth duct. With the lower required mass flow came a corresponding decrease in the heat transfer, but only by $40 \%$ as compared to the smooth duct. By comparison, the widest spaced pin fin array $(S / D=4.0, X / D=2.6)$ exhibited an $80 \%$ reduction in mass flow, with only a $30 \%$ decrease in the heat transfer. When analyzed with a constant pressure ratio, the high friction factor augmentation from the L-PBF pin fin arrays caused by the rough surface finish is redeemed by the high heat transfer augmentation.

\section{Conclusions}

Four microchannel pin fin arrays were manufactured using L-PBF and experimentally investigated for pressure loss and heat transfer performance. Additionally, the test coupons were CT scanned and the internal features of the arrays were analyzed. The test coupons showed extremely high roughness on both top and bottom endwall surfaces. The surface roughness appeared to be a function of the number of pins in the array; as pin density increased, a corresponding increase in the roughness in the channel was seen due to the higher levels of heat accumulation during the build. With the larger amount of exposed surface area per build layer, more loose powder particles may have more readily adhered to the interior channel surfaces.

The positive trend in roughness correlated with the positive trend seen in the friction factor results, which does not agree with trends from previous studies in the literature. In smooth pin fin arrays, friction factor is generally influenced by spanwise spacing and not affected by variations in streamwise spacing. The increase in friction factor between two L-PBF coupons with the same spanwise spacing, but different streamwise spacing, was therefore attributed to the difference in surface roughness levels. When compared to their smooth pin fin array counterparts, the L-PBF arrays showed an increase in friction factor of $20-80 \%$ (for a tighter spanwise spacing) and $60 \%$ (for a wider spanwise spacing) over smooth arrays with the same spanwise spacing.

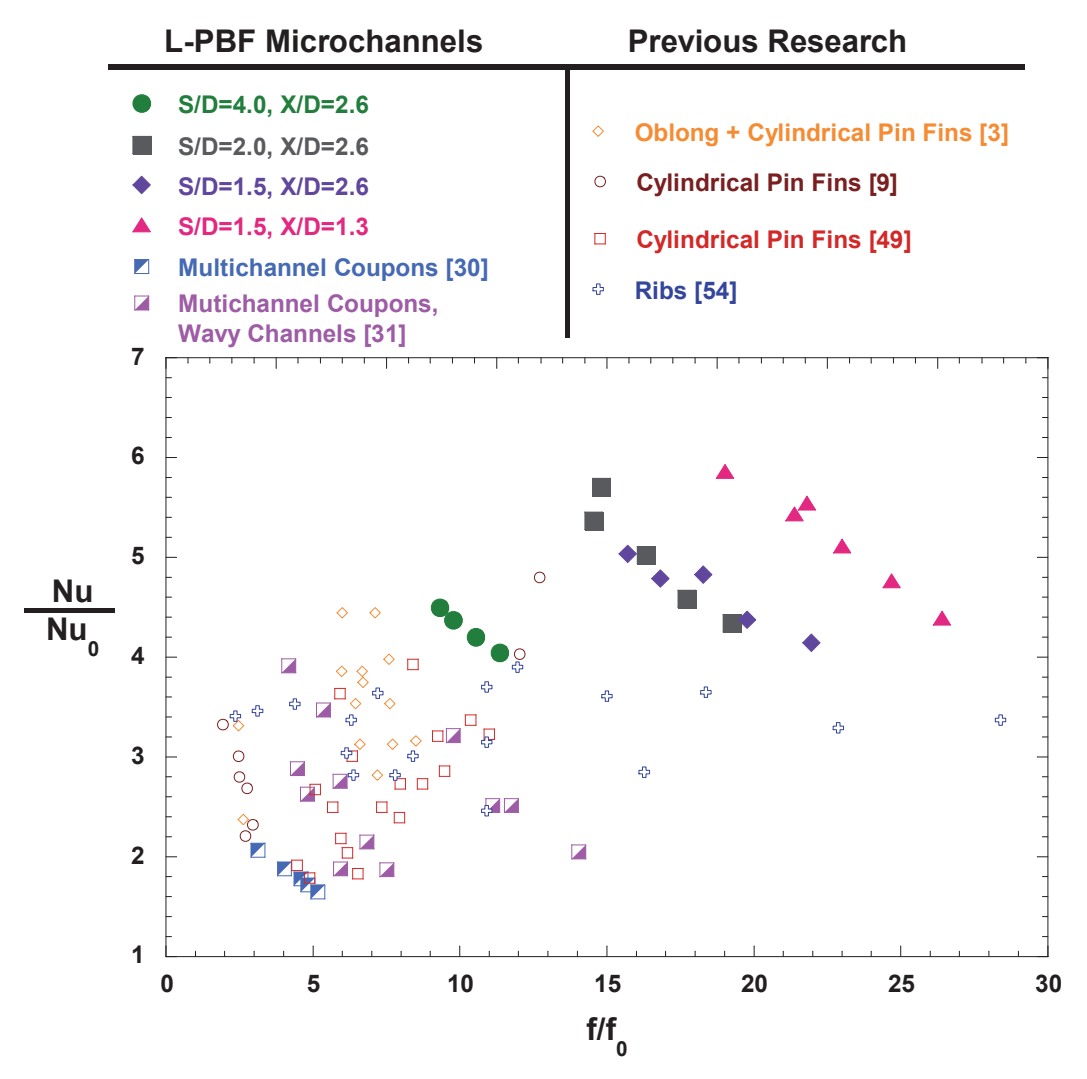

Figure 19. Nusselt Number augmentation vs. friction factor augmentation for the four L-PBF pin fin arrays from the present study, select smooth walled pin fin arrays and other L-PBF internal cooling schemes.

The heat transfer augmentation of the L-PBF coupons far exceeded that of a smooth channel. Additionally, the heat transfer dependence on both streamwise and spanwise spacing in the L-PBF pin fin arrays agreed with reports from the literature; a significant decrease in the spanwise spacing led to a measureable increase in the heat transfer, while a 
slight decrease in spanwise spacing led to a marginal increase in the heat transfer. Decreasing the streamwise spacing also led to an increase in the heat transfer. The wake interactions in the arrays were beneficial to the heat transfer performance, regardless of surface finish.

In directly comparing the L-PBF coupons to their smooth array counterparts, the spanwise spacing proved to have a strong effect. At a close spanwise spacing, the L-PBF coupon outperformed other smooth arrays with the same spacing, especially at higher Reynolds numbers. With a wider spanwise spacing, however, the difference between the L-PBF and smooth arrays was small. An important mechanism in heat transfer from a pin fin array is the pin wake interactions; the rough surfaces work to exacerbate those interactions, but only for spanwise spacings close enough for the wakes to influence one another.

In comparing the four L-PBF pin fin arrays from the current study to other studies from the literature, the friction factor from the current test coupons was extremely high, with only a marginal benefit in heat transfer. The L-PBF coupon with a wide spanwise spacing showed the lowest friction factor of the four coupons, with a similar heat transfer performance. Put another way, the array with the fewest pins exhibited similar heat transfer performance to the array that contained six times the number of pins. Such a reduction in the number of pin fins could lead to measureable decrease in engine component weight and material requirements. If L-PBF becomes the chosen method for manufacturing pin arrays, this study has found that roughness levels and pin shape are intrinsically tied to the pin spacing in the array and prove equally influential in the performance of the array; fewer pins in an array can provide better overall performance than a densely-packed array.

Designing for additive manufacturing requires a different thought process and a full understanding of the benefits and drawbacks of the technique. With more fundamental research on what can be expected from the L-PBF process as it relates to conventional cooling schemes, the high surface roughness can be exploited to achieve more efficient heat exchangers.

\section{Acknowledgements}

The authors would like to thank the National Science Foundation for the financial support of this study; this material is based upon work supported by the National Science Foundation Graduate Research Fellowship Program under Grant No. DGE1255832. Additionally, the manufacturing of the test coupons and the evaluation of their internal features were made possible by the efforts of Corey Dickman and Griffin Jones at Penn State's CIMP-3D. The authors are truly grateful for their time. 


\section{Nomenclature}

\begin{tabular}{|c|c|}
\hline$A_{c}$ & cross sectional area \\
\hline$A_{f}$ & surface area of fin \\
\hline$A_{s}$ & wetted surface area \\
\hline$A_{t}$ & total surface area \\
\hline D & pin diameter \\
\hline$D_{h}$ & channel hydraulic diameter, $4 \cdot A_{c} \cdot p^{-1}$ \\
\hline$f$ & friction factor \\
\hline$f_{0}$ & empty duct friction factor, \\
\hline h & convective heat transfer coefficient \\
\hline $\mathrm{H}$ & pin height or channel height \\
\hline k & thermal conductivity \\
\hline $\mathrm{L}$ & channel length \\
\hline $\mathrm{L}_{c}$ & characteristic length \\
\hline $\mathrm{m}$ & $\delta\left[h \cdot p \cdot\left(k \cdot A_{c}\right)^{-1}\right]$ \\
\hline$N$ & number of pin fin rows \\
\hline$N_{\text {pins }}$ & number of pin fins in array \\
\hline $\mathrm{Nu}$ & Nusselt number, $\mathrm{h} \cdot \mathrm{D} \cdot \mathrm{k}_{\mathrm{air}}{ }^{-1}$ \\
\hline Nuo & Empty duct Nusselt number, \\
\hline $\mathrm{p}$ & channel perimeter \\
\hline$P$ & static pressure \\
\hline Q & heat into system \\
\hline $\mathrm{R}_{\mathrm{a}}$ & arithmetic mean surface roughness, \\
\hline $\operatorname{Re}_{\mathrm{D}}$ & pin Reynolds number, $U_{\max } \cdot D \cdot v^{-1}$ \\
\hline $\operatorname{Re}_{\mathrm{Dh}}$ & duct Reynolds number, $\mathrm{U}_{\mathrm{m}} \cdot \mathrm{D}_{\mathrm{h}} \cdot \mathrm{v}^{-1}$ \\
\hline$S$ & spanwise spacing \\
\hline$\Delta \mathrm{T}_{\mathrm{lm}}$ & log mean temperature difference \\
\hline $\mathrm{U}_{\mathrm{m}}$ & mean channel velocity \\
\hline $\mathrm{U}_{\max }$ & maximum channel velocity \\
\hline W & channel width \\
\hline $\mathrm{X}$ & streamwise spacing \\
\hline
\end{tabular}

\section{Greek}

$€ \quad$ sand grain roughness 
v Air kinematic viscosity

$\rho \quad$ Air density

$\eta_{f} \quad$ fin efficiency, $\eta_{f}=\tanh \left(m \cdot L_{c}\right) \cdot\left(m \cdot L_{c}\right)^{-1}$

$\eta_{0} \quad$ Overall surface efficiency, $\eta_{o}=1-\left(N_{\text {pins }} A_{f}\right) \cdot\left(1-\eta_{f}\right) \cdot A_{t}{ }^{-1}$ 


\section{References}

[1] Chyu, M. K., and Moon, H. K., 2009, "Effects of Height-to-Diameter Ratio of Pin Element on Heat Transfer from Staggered Pin-Fin Arrays," ASME Paper No. GT2009-59814.

[2] Metzger, D. E., Shepard, W. B., and Haley, S. W., 1986, "Row Resolved Heat Transfer Variations in Pin-Fin Arrays Including Effects of NonUniform Arrays and Flow Convergence," ASME Paper No. 86-GT-132.

[3] Metzger, D. E., Fan, C. S., and Haley, S. W., 1984, "Effects of Pin Shape and Array Orientation on Heat Transfer and Pressure Loss in Pin Fin Arrays,” J. Eng. Gas Turbines Power, 106(1), p. 252.

[4] Simoneau, R. J., and VanFossen, G. J., 1984, "Effect of Location in an Array on Heat Transfer to a Short Cylinder in Crossflow," J. Heat Transfer, 106(1), p. 42.

[5] VanFossen, G. J., 1982, “Heat-Transfer Coefficients for Staggered Arrays of Short Pin Fins," J. Eng. Power, $104(2)$, p. 268.

[6] Armstrong, J., and Winstanley, D., 1988, "A Review of Staggered Array Pin Fin Heat Transfer for Turbine Cooling Applications," J. Turbomach., 110(1), p. 94.

[7] Ostanek, J. K., 2015, “Improving Pin-Fin Heat Transfer Predictions Using Artificial Neural Networks," ASME Paper No. GT2013-95903.

[8] Lyall, M. E., Thrift, A. A., Thole, K.A., Kohli, A., 2011, “Heat Transfer from Low Aspect Ratio Pin Fins,” J. Turbomach, 133, p. 011001 (10 pages).

[9] Lawson, S. A., Thrift, A. A., Thole, K. A., and Kohli, A., 2011, "Heat transfer from multiple row arrays of low aspect ratio pin fins," Int. J. Heat Mass Transf., 54(2011), pp. 4099-4109.

[10] Siw, S. C., Fradeneck, A. D., Chyu, M. K., and Alvin, M. A., 2015, "The Effects of Different Pin-Fin Arrays on Heat Transfer and Pressure Loss in a Narrow Channel," GT2015-43855, pp. 1-9.

[11] Ashman, S., and Kandlikar, S. G., 2006, "A Review of Manufacturing Processes for Microchannel Heat Exchanger Fabrication," ASME 4th Int. Conf. Nanochannels, Microchannels, Minichannels, Parts A B, 2006, pp. 855-860.

[12] Marques, C., and Kelly, K. W., 2004, "Fabrication and Performance of a Pin Fin Micro Heat Exchanger," J. Heat Transfer, 126(June), p. 434.

[13] İzci, T., Koz, M., and Kosar, A., 2015, "The Effect of Micro Pin-Fin Shape on Thermal and Hydraulic Performance of Micro Pin-Fin Heat Sinks," Heat Transf. Eng., 36(May), pp. 1447-1457.

[14] Jasperson, B. a., Turner, K. T., and Pfefferkorn, F. E., 2010, “Comparison of Micro-Pin-Fin and Microchannel Heat Sinks Considering ThermalHydraulic Performance and Manufacturability,” IEEE Trans. Components Packag. Technol., 33(1), pp. 148-160.

[15] Heo, K. Y., Kihm, K. D., and Lee, J. S., 2014, "Fabrication and experiment of micro-pin-finned microchannels to study surface roughness effects on convective heat transfer," J. Micromechanics Microengineering, 24(12), p. 125025.

[16] Chang, S. W., and Lees, A. W., 2010, “Endwall heat transfer and pressure drop in scale-roughened pin-fin channels,” Int. J. Therm. Sci., 49(4), pp. 702-713.

[17] Snyder, J. C., Stimpson, C. K., Thole, K. A., and Mongillo, D., 2016, "Build Direction Effects on Additively Manufactured Channels," J. Turbomach, 138(5), p. 051006.

[18] Cormier, Y., Dupuis, P., Farjam, A., Corbeil, A., and Jodoin, B., 2014, “Additive manufacturing of pyramidal pin fins: Height and fin density effects under forced convection," Int. J. Heat Mass Transf., 75, pp. 235-244.

[19] Dupuis, P., Cormier, Y., Fenech, M., and Jodoin, B., 2016, "Heat transfer and flow structure characterization for pin fins produced by cold spray additive manufacturing," Int. J. Heat Mass Transf., 98, pp. 650-661.

[20] Dupuis, P., Cormier, Y., Fenech, M., Corbeil, A., and Jodoin, B., 2016, "Flow structure identification and analysis in fin arrays produced by cold spray additive manufacturing," Int. J. Heat Mass Transf., 93, pp. 301-313.

[21] Ventola, L., Robotti, F., Dialameh, M., Calignano, F., Manfredi, D., Chiavazzo, E., and Asinari, P., 2014, "Rough surfaces with enhanced heat transfer for electronics cooling by direct metal laser sintering," Int. J. Heat Mass Transf., 75, pp. 58-74.

[22] Wong, M., Owen, I., Sutcliffe, C. J., and Puri, A., 2009, "Convective heat transfer and pressure losses across novel heat sinks fabricated by Selective Laser Melting," Int J Heat Mass Transf., 52(1-2), pp. 281-288.

[23] Dede, E. M., Joshi, S. N., and Zhou, F., 2015, "Topology Optimization, Additive Layer Manufacturing, and Experimental Testing of an AirCooled Heat Sink,” J. Mech. Des., 137(November), pp. 1-9.

[24] Ning, Y., Wong, Y. S., Fuh, J. Y. H., and Loh, H. T., 2006, “An approach to minimize build errors in direct metal laser sintering," IEEE Trans. Autom. Sci. Eng., 3(1), pp. 73-80.

[25] Khaing, M. W., Fuh, J. Y. H., and Lu, L., 2001, "Direct Metal Laser Sintering for Rapid Tooling: Processing and Characterisation of EOS Parts," J. Mater. Process. Technol., 113(1-3), pp. 269-272.

[26] Delgado, J., Ciurana, J., and Rodríguez, C. A., 2012, “Influence of process parameters on part quality and mechanical properties for DMLS and SLM with iron-based materials," Int. J. Adv. Manuf. Technol., 60(5-8), pp. 601-610.

[27] Strano, G., Hao, L., Everson, R. M., and Evans, K. E., 2013, "Surface roughness analysis, modelling and prediction in selective laser melting,” J. Mater. Process. Technol., 213(4), pp. 589-597.

[28] Wegner, A., and Witt, G., 2012, "Correlation of process parameters and part properties in laser sintering using response surface modeling," Phys. Procedia, 39(May 2016), pp. 480-490.

[29] Yadroitsev, I., and Smurov, I., 2011, "Surface morphology in selective laser melting of metal powders," Phys. Procedia, 12(1), pp. 264-270.

[30] Stimpson, C. K., Snyder, J. C., Thole, K. A., and Mongillo, D., 2016, "Roughness Effects on Flow and Heat Transfer for Additively Manufactured Channels," J. Turbomach, 138(5), p. 051008.

[31] Kirsch, K. L., and Thole, K. A., 2017, "Heat Transfer and Pressure Loss Measurements in Additively Manufactured Wavy Microchannels," J. Turbomach, 139(1), p. 011007.

[32] Norris, R. J., 1971, Some Simple Approximate Heat Transfer Correlations for Turbulent Flow in Ducts with Surface Roughness, American Society of Mechanical Engineers M4 - Citavi, New York.

[33] Pakkanen, J., Calignano, F., Trevisan, F., Lorusso, M., Ambrosio, E. P., Manfredi, D., and Fino, P., 2016, "Study of Internal Channel Surface Roughnesses Manufactured by Selective Laser Melting in Aluminum and Titanium Alloys," Metall. Mater. Trans. A, 47(3837).

[34] Bacchewar, P. B., Singhal, S. K., and Pandey, P. M., 2007, "Statistical modelling and optimization of surface roughness in the selective laser sintering process," Proc. Inst. Mech. Eng. Part B-Journal Eng. Manuf., 221(1), pp. 35-52.

[35] Jamshidinia, M., and Kovacevic, R., 2015, "The influence of heat accumulation on the surface roughness in powder-bed additive manufacturing,” Surf. Topogr. Metrol. Prop., 3(1), p. 014003.

[36] Stimpson, C. K., Snyder, J. C., and Thole, K. A., 2016, "Scaling Roughness Effects on Pressure Loss and Heat Transfer of Additively 
Manufactured Channels," J. Turbomach, 139(2), p. 021003 (10 pages).

[37] Huang, K., Wan, J. W., Chen, C. X., Li, Y. Q., Mao, D. F., and Zhang, M. Y., 2013, "Experimental investigation on friction factor in pipes with large roughness," Exp. Therm. Fluid Sci., 50, pp. 147-153.

[38] Dai, B., Li, M., and Ma, Y., 2014, "Effect of surface roughness on liquid friction and transition characteristics in micro- and mini-channels," Appl. Therm. Eng., 67(1), pp. 283-293.

[39] Kandlikar, S. G., Schmitt, D., Carrano, A. L., and Taylor, J. B., 2005, "Characterization of Surface Roughness Effects on Pressure Drop in Single-Phase Flow in Minichannels," Phys. Fluids, 17(2005), p. 100606.

[40] EOS GmbH, 2014, "EOS NickelAlloy IN718 for EOSINT M 270 Systems," p. 6 T4 - Material data sheet M4.

[41] EOS GmbH, "EOSINT M 280 System Data Sheet."

[42] 2014, "Volume Graphics MAX."

[43] Incropera, F. P., DeWitt, D. P., Bergman, T. L., and Lavine, A. S., 2007, Fundamentals of Heat and Mass Transfer, John Wiley \& Sons.

[44] Weaver, S. A., Barringer, M. D., and Thole, K. A., 2011, “Microchannels With Manufacturing Roughness Levels," J. Turbomach., 133(4), p. 41014.

[45] AliCat, 2014, "Mass Flow Controller - Operating Manual."

[46] Kline, S. J., and McClintock, F. A., 1953, "Describing the uncertainties in single sample experiments," Mech. Eng., pp. 3-8.

[47] Colebrook, C. F., and White, C. M., 1937, "Experiments with Fluid Friction in Roughened Pipes," Proc. R. Soc. Lond. A. Math. Phys. Sci., 161(906), pp. 367-381.

[48] Gnielinski, V., 1975, “New equations for heat and mass transfer in turbulent pipe and channel flow,” Int. Chem. Eng., 16(2), pp. 359-368.

[49] Ostanek, J. K., 2012, "Flowfield Interactions in Low Aspect Ratio Pin-Fin Arrays," The Pennsylvania State University.

[50] Brigham, B. A., and VanFossen, G. J., 1984, "Length to Diameter Ratio and Row Number Effects in Short Pin Fin Heat Transfer," J. Eng. Gas Turbines Power, 106(1), p. 241.

[51] Damerow, W. P., Murtaugh, J. C., and Burgraff, 1972, "Experimental and Analytical Investigation of the Coolant Flow Characteristics in Cooled Turbine Airfoils," NASA CR-120883.

[52] Jacob, M., 1938, "Heat Transfer and Flow Resistance in Cross Flow of Gases over Tube Banks," Trans ASME, 59, pp. 384-386.

[53] Ostanek, J. K., and Thole, K. A., 2012, "Wake development in staggered short cylinder arrays within a channel," Exp. Fluids.

[54] Wright, L. M., Fu, W. L., and Han, J. C., 2004, "Thermal Performance of Angled, V-Shaped, and W-Shaped Rib Turbulators in Rotating Recatngular Cooling Channels (AR=4:1),” J. Turbomach., 124(4), pp. 604-614. 